lateral skull $x$ ray film in one patient or by changes in the computed tomogram or air encephalogram in the other three patients. Case 3 required five sequential computed tomograms and an air encephalogram during a period of $5 \cdot 5$ years before the tumour was imaged. In two of our patients (cases 1 and 3 ) the interval between the onset of symptoms and diagnosis was greater than four years, ${ }^{3}$ and in one this delay was 11.2 years. This delay occurred in spite of the recent technological advances in neuroradiological imaging.

These cases illustrate the importance of both endocrine and neuroradiological follow up in children with apparently isolated diabetes insipidus, particularly if the risk of permanent visual loss due to a tumour is to be avoided. While diabetes insipidus may be familial ${ }^{4}$ or associated with other congenital abnormalities of the brain, ${ }^{5}$ the more usual aetiologies are those of intracranial tumour or histiocytosis. The onset of diabetes insipidus in midchildhood-especially if combined with growth failure-should never be considered idiopathic. Such cases require careful follow up using high resolution computed tomography ${ }^{6}$ and possibly nuclear magnetic resonance imaging, if necessary into adult life.

We are grateful to Dr D M Flynn, The Royal Free Hospital, London, for his help with case 3 .

\section{References}

1 Preece MA. Growth hormone deficiency. In: Brook CGD, ed. Clinical paediatric endocrinology. Oxford: Blackwell Scientific, 1981:285-304.

${ }^{2}$ Hanna CE, LaFranchi SH. Evolving hypopituitarism in children with central nervous system lesions. Pediatrics 1983;72:65-70.

${ }^{3}$ Pomarède R, Czernichow P, Rappaport R, Royer P. Le diabète insipide pitresso-sensible de l'enfant. II. Etude de 93 cas observe's entre 1955 et 1978. Arch Fr Pediatr 1980;37:37-44.

${ }^{4}$ Martin FIR. Familial diabetes insipidus. $Q \mathrm{~J}$ Med 1959;28: 573-82.

5 Stanhope R, Preece MA, Brook CGD. Hypoplastic optic nerves and pituitary dysfunction: a spectrum of anatomical and endocrine abnormalities. Arch Dis, Child 1984;59:111-4.

${ }^{6}$ Stanhope R, Hindmarsh P, Kendall B, Brook CGD. High resolution CT scanning of the pituitary gland in growth disorders. Acta Paediatr Scand 1986;75:779-86.

Correspondence to Dr R Stanhope, Department of Growth and Development, Institute of Child Health, 30 Guilford St, London WC1N 1EH.

Received 9 July 1986

\title{
Height in epilepsy
}

\author{
H TADA, S J WALLACE, AND I A HUGHES \\ Department of Child Health, University Hospital of Wales, Cardiff
}

SUMMARY Longitudinal data on the height of prepubertal children with epilepsy are presented. Although both seizures and antiepileptic drugs may affect serum hormone concentrations, linear growth remains normal.

Serum hormone concentrations can be affected by both seizures ${ }^{1}$ and antiepileptic drugs. ${ }^{2}$ Suboptimal adult height after somewhat early puberty has been reported in children who attended a residential school because of epilepsy. ${ }^{3}$ We report on the stature of children with chronic seizure disorders who live at home and attend local schools.

\section{Patients and methods}

The medical records of all children with epilepsy who attended the paediatric neurology clinic at our hospital between May and July 1985 were examined. The present data relate to 51 children ( 29 girls) who had been assessed when aged 2 to 11 years. Clinical details are given in the Table. Measurements for standing height, using a Harpenden Stadiometer, were available at six monthly intervals. Data from boys and girls were analysed separately.

As calculation of mean trends in mixed longitudinal data, based on mean values at each age, gives inefficient estimates ${ }^{4}$ the age at which the largest numbers of children were measured was selected (8.0 years for girls and 9.5 years for boys) and the mean heights at this age calculated. Individual increments in height were calculated for each six months and the mean increment successively added to or subtracted from the mean height referred to previously. ${ }^{5}$ This method obviates bias effects from single height measurements from unusually tall or short children. More boys and girls were older rather than younger than the reference age. Data were available at 11 years for 14 boys and 10 girls. The parental heights were ascertained in eight cases in whom seizures had been life long and measurements were available at 11 years. 
Table Clinical details of the subjects studied

\begin{tabular}{lcc}
\hline & $\begin{array}{l}\text { Boys } \\
(n=22)\end{array}$ & $\begin{array}{l}\text { Girls } \\
(n=29)\end{array}$ \\
\hline Predominant seizure type: & & \\
Generalised tonic-clonic & 5 & 5 \\
Myoclonic syndrome & 7 & 7 \\
Absence & 1 & 3 \\
Simple partial & - & 2 \\
Complex partial & 8 & 12 \\
Photosensitive & 1 & - \\
& & \\
Antiepileptic drug treatment: & 1 & - \\
None & 7 & 9 \\
Barbiturates (including primidone) & 6 & 15 \\
Phenytoin & 8 & 2 \\
Carbamazepine & 8 & 6 \\
Valproate & 1 & 14 \\
Ethosuximide & 8 & 2 \\
Benzodiazepines & 10 & \\
Receiving two drugs & 2 & 16 \\
Receiving three or more drugs & & 18 \\
& & 23 \\
Age at onset of seizures: & 13 & \\
Before 2 years & 18 & \\
Before 5 years & 20 & \\
Before 7 years & & \\
\hline
\end{tabular}

\section{Results}

Figures (a) and (b) show the mean standing heights plotted at six monthly intervals for boys and girls, respectively. The longitudinal curve for boys was between the 25th and 50th centiles for normal boys aged 2 to 11 years. For girls, the growth curve was between the 50th and 75th centiles. There is no evidence of an early onset of pubertal growth in either sex. The eight children measured at 11 years whose seizures had started in infancy and for whom parental heights were available were growing in keeping with their familial expectations. Subgroups of children with a specific type of seizure, with a high seizure frequency, or receiving particular antiepileptic drugs had growth curves similar to the total group.

\section{Discussion}

Early puberty and subopti:nal height attainment has been noted in children with epilepsy in a residential school. ${ }^{3}$ It has been suggested that the epilepsy in these cases might be particularly severe as only $0.5 \%$ of British children with epilepsy attend residential schools. Many of the children in the present study were severely affected and were having frequent daily seizures, but they were living at home and attending day schools. Their growth pattern throughout childhood was within normal limits and puberty did not occur early. It is concluded that seizure frequency does not influence height attainment and that the suboptimal growth of children educated away from home may be related more to concurrent social problems than to epilepsy.

A rise in serum prolactin concentration follows generalised tonic-clonic seizures. ${ }^{1}$ Although the rise in growth hormone concentrations is less consistent, there is increased growth hormone responsiveness to stimulation with clonidine after seizures. ${ }^{1}$ Despite
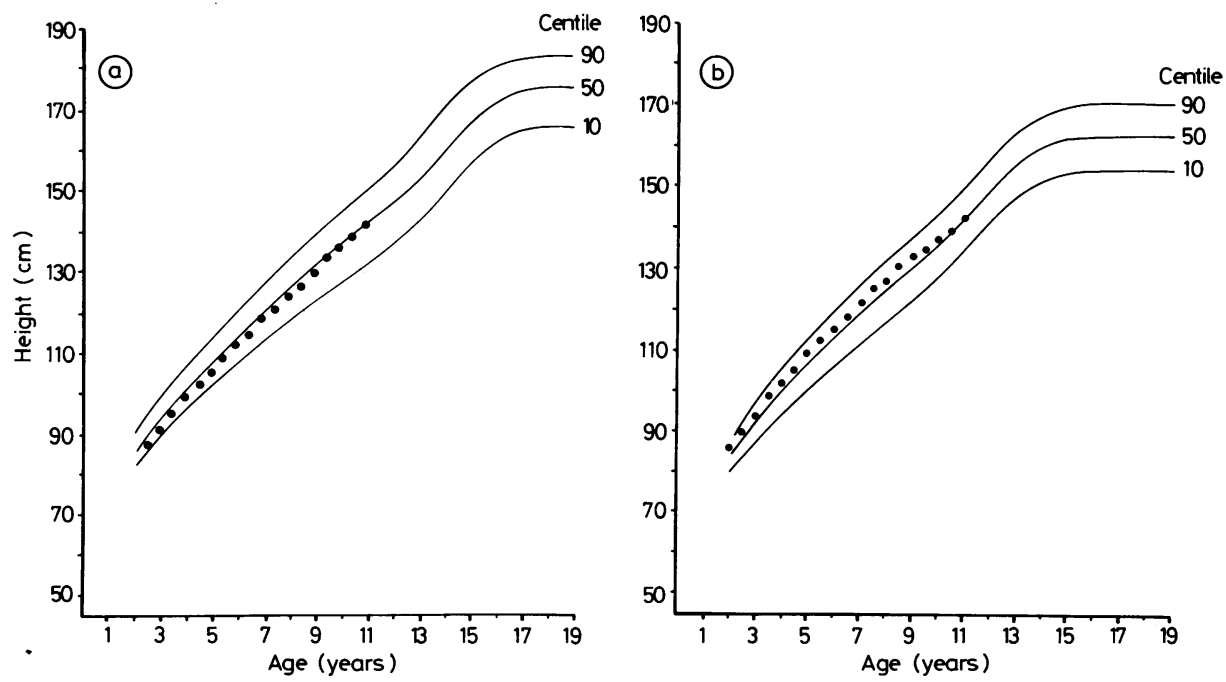

Figure Linear growth in (a) boys and (b) girls with epilepsy. The normal 10th, 50th, and 90th centiles from Tanner height standard charts are shown for comparison. 
these reports, we found no evidence that the growth in children with frequent generalised tonic-clonic seizures was impaired relative to those who had infrequent partial seizures.

Phenytoin, phenobarbitone, carbamazepine, and valproate increase the metabolism of sex hormones and enhance the synthesis of sex hormone binding globulin in the liver. ${ }^{2}$ In boys the increase in sex hormone binding globulin leads to an increase in total testosterone concentration, but the concentration of the free fraction remains unaltered. ${ }^{2}$ In adult women increases in serum growth hormone have been noted during treatment with carbamazepine and phenytoin, but the rise in growth hormone caused by insulin hypoglycaemia may be less than expected in adults on antiepileptic drugs. ${ }^{2}$ Comparable data are not available for children. It has been postulated that short stature, which has been reported in adult men with epilepsy, ${ }^{6}$ might be consequent on the use of phenytoin in childhood, but our evidence suggests that antiepileptic drugs do not have clinically important effects on height attainment up to puberty.
The helpful advice from Professor MA Preece for the analysis of the growth data is gratefully acknowledged.

\section{References}

1 Meldrum BS, McWilliam JR. Hormone changes following seizures. In: Dam M. Gram L. Pewry JK. Advances in epileptology: XIIth Epilepsy International Symposium. New York: Raven Press, 1981:441-8.

2 Fichsel H. Hormonal changes in children receiving antiepileptic drugs. In: Dam M. Gram L. Pewry JK. Advances in epileptology: XIIth Epilepsy International Symposium. New York: Raven Press, 1981:449-59.

${ }^{3}$ Round JM. Growth, development and biochemical changes during puberty in a population of epileptic children. In: Dam M, Gram L. Pewry JK. Advances in epileptology: XIIth Epilepsy International Symposium. New York: Raven Press, 1981:461-7.

4 Tanner JM. Notes on the reporting of growth data. Hum Biol 1951:23:93-159.

5 Tanner JM. Gupta D. A longitudinal study of the urinary excretion of individual steroids in children from 8 to 12 years old. Journal of Endocrinology 1968:41:139-56.

- McGowan MEL. Final adult height of patients with epilepsy. Dev Med Child Neurol 1983;25:591-4

Correspondence to Dr S J Wallace, Department of Paediatrics, University Hospital of Wales, Heath Park, Cardiff CF4 4XW, Wales

Reccived 1 August 1986

\title{
Preoperative stabilisation in congenital diaphragmatic hernia
}

\author{
P H T CARTLIDGE, N P MANN, AND L KAPILA \\ Department of Neonatal Medicine and Surgery, City Hospital, Nottingham
}

SUMmaRY Critically ill infants with congenital diaphragmatic hernia were treated by either early surgery or delayed surgery after preoperative stabilisation. The preoperative stabilisation was aimed at correcting acidosis and hypoxia, thereby reducing the severity of persistent fetal circulation. Survival improved from $12.5 \%$ after early surgery to $52.9 \%$ after delayed surgery.

Infants with congenital diaphragmatic hernia often have severe acidosis and hypoxia at presentation. Immediate repair may lead to an improvement, but many infants deteriorate with increasing hypoxia, dying after a 'honeymoon period' of about 18 hours. This deterioration is usually due to persistent fetal circulation, which is a consequence of hypoxia, acidosis, and the innately abnormal pulmonary arterioles, which are more muscular and reduced in number. ${ }^{12}$ Recent reports have suggested that preoperative treatment aimed at correcting acidosis, hypoxia, and tissue hypoperfusion decreases the severity of persistent fetal circulation and improves survival. $^{3-5}$ In 1983 we adopted this new management approach. This paper reports our results.

\section{Patients and methods}

From January 1981 to November 1985, 33 infants with congenital diaphragmatic hernia presenting within two hours of birth were treated in our department; their details are shown in Table 1.

Before August 1983, 16 infants were treated with early surgery. Preoperatively most were ventilated only briefly while surgery was organised. Stomach aspiration was used to decompress the bowel. Metabolic acidosis was treated with sodium bicarbonate.

After August 1983, 17 infants were treated with delayed surgery after a period of preoperative stabilisation. Infants in respiratory failure were paralysed with tubocurare and ventilated using low pressures and high rates. Stomach aspiration was again performed. Arterial and venous catheters were inserted through the umbilical vessels. The 